\title{
Post-Modification of the Electronic Properties by Addition of $\pi$-Stacking Additives in N-Heterocyclic Carbene Complexes with Extended Polyaromatic Systems
}

\author{
Hugo Valdés, Macarena Poyatos, ${ }^{*}$ and Eduardo Peris* \\ Departamento de Química Inorgánica y Orgánica, Universitat Jaume I, Av. Vicente Sos Baynat s/n, 12071-Castellón, \\ Spain; eperis@uji.es.Fax: (+)34964387522 \\ KEYWORDS Iridium $•$ pyrene $\cdot N$-heterocyclic carbene $\bullet \pi$-stacking $\bullet$ Tolman Electronic Parameter $・ J o b ~ p l o t$
}

\begin{abstract}
A series of iridium complexes containing phenanthro[4,5-abc]phenazino[11,12-d]imidazol-2-ylidene and acetonaphtho[1,2-b]quinoxaline[11,12-d]imidazol-2-ylidene ligands have been obtained and fully characterized. These complexes display highly extended polyaromatic systems attached to the backbone of the N-heterocyclic carbene. The presence of this extended polyaromatic system makes the electron-donating character of these ligands sensitive to the presence of $\pi$-stacking additives, such as pyrene and hexafluorobenzene. The computational studies predict that the addition of pyrene affords an increase of the electron-donating character of the polyaromatic ligand (TEP decreases), while the addition of hexafluorobenzene has the opposite effect (TEP increases). This prediction is experimentally corroborated by IR spectroscopy, by measuring the shift of the $\mathrm{CO}$ stretching bands of a series of $\operatorname{IrCl}(\mathrm{NHC})(\mathrm{CO})_{2}$ complexes, where $\mathrm{NHC}$ is the $\mathrm{N}$-heterocyclic carbene ligand with the polyaromatic system. Finally, the energy of the $\pi$-stacking interaction of one of the key $\operatorname{Ir}(\mathrm{I})$ complexes with pyrene and hexafluorobenzene has been estimated by using the Benesi-Hildebrand treatment, based on the $\delta$-shifts observed by ${ }^{1} \mathrm{H}$ NMR spectroscopy.
\end{abstract}

\section{INTRODUCTION}

Transition metal complexes with N-heterocyclic carbene ligands decorated with polyaromatic systems are currently under great attention due to their potential applications in the fields of homogeneous catalysis and molecular electronics. In the field of molecular electronics, polyaromatic ligands are mainly used for the preparation of materials with properties that are consistent with extensively delocalized systems, ${ }^{1}$ such as luminescence. ${ }^{2}$ Polyaromatic-fused imidazolylidenes provide rigid frameworks in which the carbene center is a component of an electron-rich extended aromatic system, and this modulates the donor strength of the carbene and influences its steric impact. A series of polyannulated mono-, bis- and tris-NHCs have been reported to date, including examples having 4,5 -fused polyarenes such as naphthalene, phenanthrene, ${ }^{3}$ acetanaphtene, ${ }^{4}$ pyracene, ${ }^{5}$ pyrene ${ }^{6}$ and triphenylene. ${ }^{7}$

An interesting application of NHC ligands with extended aromatic systems in the field of catalysis, arises from the ability of this type of ligands to facilitate the immobilization of homogeneous catalysts onto solid surfaces, in which the polyaromatic tags are used for facilitating noncovalent interactions (generally $\pi$-stacking) with the surface of the solid (generally a graphene derivative). ${ }^{8}$ The use of NHC ligands with extended polyaromatic systems have also given rise to families of metal complexes whose properties are influenced by the $\pi$-stacking affinities of the substrates with the ligands..$^{5 b, 6 a, 7 a, 8 e}$ We recently tried to rationalize the effects of $\pi$-stacking on the catalytic properties of a series of catalysts of palladium with extended polyaromatic systems at the backbone of the NHC ligand, and proved that the addition of $\pi$-stacking additives, such as pyrene, had an important influence on their catalytic performances. An interesting point of our investigation, arose from the cyclic voltammetric studies of our complexes, which demonstrated that the presence of external $\pi$-stacking additives showed important modifications of the electronic properties of the ligands, as a consequence of the strong $\pi$-stacking interaction between pyrene and the extended polyaromatic system attached to the NHCs. ${ }^{6 a}$ The effects of modifying the electronic properties of NHCs ligands are known to afford important implications in the context of homogeneous catalysis and bioorganometallic chemistry, ${ }^{9}$ and some elegant examples of fine electronic tuning of NHC ligands via remote chemical induction have shown to produce relevant effects in catalysis. ${ }^{10}$

Benzo-fused nitrogen heterocycles continue to command a great deal of attention because a large number of natural products and pharmaceutical compounds incorporate these heterocyclic systems." In a very recent work, Tapu and co-workers described the preparation of a diaminobenzimidazolium salt, which constituted an excellent scaffold for the preparation of NHC ligands with fused polycyclic heteroaromatic moieties. ${ }^{12}$ In their report, a new polycyclic $\mathrm{N}$-heterocyclic carbene featuring a fused 
dibenzo[a,c]phenazine moiety was obtained (A, Chart 1), and coordinated to rhodium and iridium. ${ }^{12}$ We thought that the same diaminobenzimidazolium salt may be used for the preparation of higher extended aromatic NHCbased ligands, which may help us undergo a detailed study on the influence of $\pi$-stacking interactions on the donor properties of the related NHC ligands. By following this idea, in this work we describe the preparation of two new N-heterocyclic carbene ligands with fused phenanthro[4,5-abc]phenazine (B) and acetonaphtho[1,2b]quinoxaline $(\mathbf{C})$, which we coordinated to iridium. The luminescence properties of the salt precursors, and the study of the post-modification of the electronic effect of the NHC ligands by addition of $\pi$-stacking additives is also described.
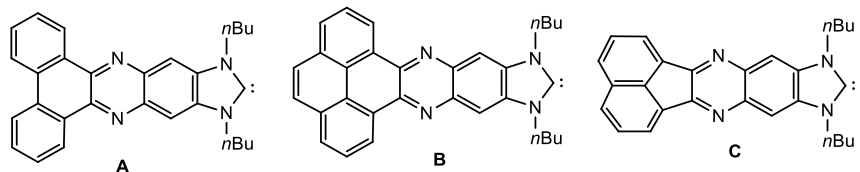

\section{Chart 1}

\section{RESULTS AND DISCUSSION}

The preparation of the azolium salts with the fused phenanthro[4,5-abc]phenazine (2) and acetonaphtho[1,2b] quinoxaline (3), was performed by condensation of 1,3dibutyl-5,6-diaminobenzimidazolium iodide (1), in yields ranging from $70-80 \%$. The benzimidazolium salt $\mathbf{1}$, was prepared according to the previously described methodology, ${ }^{12}$ although we modified the final reduction step from 1,3-dibutyl-5,6-dinitrobenzimidazolium iodide, for which we found the use of hydrazine on $\mathrm{Pd} / \mathrm{C}$ to be more convenient. In order to circumvent any halide exchange in the subsequent coordination of the carbene ligands, iodide salts $2-\mathrm{H}, 2-\mathrm{tBu}$ and 3 were reacted with $\mathrm{NH}_{4} \mathrm{PF}_{6}$ to produce anion metathesis products $2-\mathrm{H}-\mathrm{PF}_{6}, 2-\mathrm{tBu}_{-}-\mathrm{PF}_{6}$ and $3-\mathrm{PF}_{6}$, respectively (see the Supplementary Information for further details).

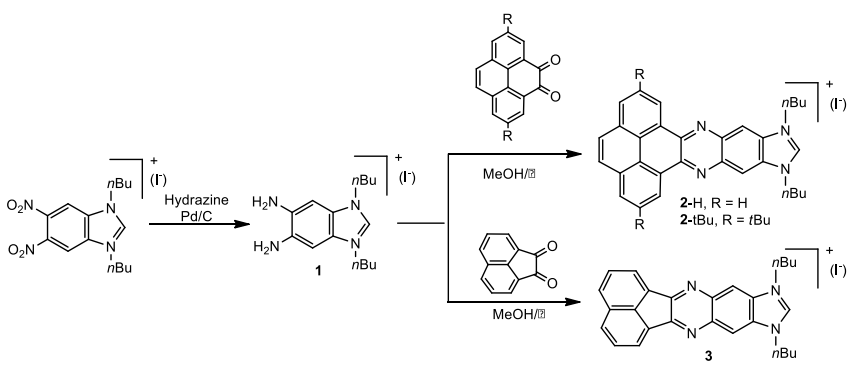

\section{Scheme 1}

The UV-vis spectroscopic properties of the iodide azolium salts were investigated and compared to those of related previously reported salts (Table 1 ). They all absorb UV-vis light at $\lambda<400 \mathrm{~nm}$, and exhibit fluorescence emission in the 450-650 $\mathrm{nm}$ region in solution. Quantum efficiencies were determined relative to quinine sulfate in 0.5
$\mathrm{M} \mathrm{H}_{2} \mathrm{SO}_{4}\left(\Phi_{\mathrm{f}}=0.546\right)$. For the azolium salts with the fused phenanthro[4,5-abc]phenazine (2), the introduction of $t \mathrm{Bu}$ groups at pyrene $(2-t \mathrm{Bu})$ resulted in a $\lambda_{\mathrm{em}}$ at $560 \mathrm{~nm}$, which is bathochromically shifted by $20 \mathrm{~nm}$ relative to 2 $\mathrm{H}$. This shift is consistent with that observed for the introduction of the $t \mathrm{Bu}$ at the 4,9 positions of pyrene, relative to unsubstituted pyrene. ${ }^{13}$ The addition of one aromatic ring in the salt 1,3dibutyldibenzo[a,c]phenazino[11,12-d]imidazolium tetrafluoroborate to yield $\mathbf{2}-\mathrm{H}$ is accompanied by a hypsochromic shift of up to $13 \mathrm{~nm}$ of the absorption maxima, as a consequence of the more delocalized $\pi$-system of $2-\mathrm{H}$ (compare entries 1 and 4). Compound 3 exhibits negligible fluorescence emission. The azolium salts $2-\mathrm{H}$ and $2-\mathrm{tBu}$ provided quantum yields $\left(\Phi_{\mathrm{f}}\right)$ of 0.25 and 0.32 , respectively.

The coordination of the polycyclic carbenes $\mathbf{B}$ and $\mathbf{C}$ to iridium was performed by deprotonation of the azolium salts 2 and 3 in THF at room temperature in the presence of $\mathrm{KO} t \mathrm{Bu}$, and subsequent addition of $[\mathrm{IrCl}(\mathrm{COD})]_{2}$. For the cases in which the iodide salts $2-\mathrm{H}, \mathbf{2}-t \mathrm{Bu}$ and 3 were used, the reaction was performed in the presence of an excess of $\mathrm{NaI}$, in order to favor the formation of the iodide metal complexes and to avoid mixtures of halides in the final metal compounds. The final products were obtained in yields ranging from $50-60 \%$.

Table 1. Photophysical properties of the synthesized salts in solution ${ }^{\mathrm{a}}$

\begin{tabular}{|c|c|c|c|c|}
\hline Entry & Compound & $\lambda_{\mathrm{abs}}(\mathrm{nm})$ & $\begin{array}{c}\lambda_{\mathrm{em}} \\
(\mathrm{nm})\end{array}$ & $\Phi_{\mathrm{f}}^{\mathrm{b}}$ \\
\hline 1 & 2-H & $243,283,345$ & 540 & 0.25 \\
\hline 2 & $2-\mathrm{tBu}$ & $249,284,351$ & 560 & 0.32 \\
\hline $3^{c}$ & 3 & 237,324 & 398 & - \\
\hline $4^{\mathrm{d}}$ & & 256,414 & 496 & 0.02 \\
\hline $5^{f}$ & & 245,275 & 370 & 0.28 \\
\hline \multicolumn{5}{|c|}{$\begin{array}{l}{ }^{\mathrm{a}} \text { Measurements were performed in } \mathrm{CH}_{3} \mathrm{CN} \text { under ambient } \\
\text { conditions. }{ }^{\mathrm{b}} \text { Emission quantum yields were measured in } \\
\text { degassed } \mathrm{CH}_{3} \mathrm{CN} \text {, with recrystallized quinine sulfate in de- } \\
\text { gassed o.5 } \mathrm{M} \mathrm{H}_{2} \mathrm{SO}_{4} \text { as standard }\left(\Phi_{\mathrm{f}}=0.546\right) \text {, exciting at } 350 \\
\text { nm. }{ }^{\mathrm{c}} \text { The emission intensity of } 3 \text { was found to be negligible. } \\
{ }^{\mathrm{d}} \text { Values taken from reference }{ }^{12} \text {. }{ }^{\mathrm{f}} \text { Values taken from reference } \\
{ }^{14} \text {. }\end{array}$} \\
\hline
\end{tabular}




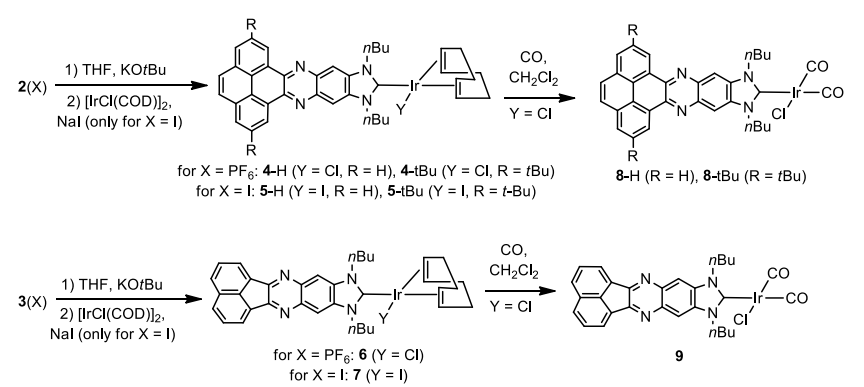

Scheme 2

The iridium complexes were characterized by NMR spectroscopy, mass spectrometry and elemental analysis. The ${ }^{1} \mathrm{H}$ NMR spectra of 4-7 displayed the characteristic signals of the pyrene ( 4 and 5$)$ and the acetonaphtene $(6$ and 7 ) fragments. The ${ }^{13} \mathrm{C}$ NMR spectra showed the characteristic signals due to the metallated carbene carbons, which for the iodide complexes appeared at 202.7 and $202.1 \mathrm{ppm}$ (for 5 - $\mathrm{H}$ and 5 -tBu, respectively), and 200.5 (for 7). In the case of the chloride complexes (4 and 6), the resonances were quasi identical to those shown by the related iodide related complexes.

The molecular structures of $\mathbf{5 - H}$ and 7 were unambiguously determined by means of X-ray diffraction. The structure of $5-\mathrm{H}$ (Figure 1), consists of a phenanthro[4,5abc]phenazino[11,12-d]imidazol-2-ylidene ligand bound to an iridium(I) center, which completes its coordination sphere with a iodide and a cyclooctadiene ligand (Figure 1). The crystal packing of the molecule shows that there is a one-dimensional $\pi$-stacking interaction between pairs of molecules, which are disposed in an antiparallel centrosymmetric fashion, at a distance of $3.37 \AA$. The NHC ligand is quasi-orthogonally oriented with respect to the coordination plane of the molecule, as evidenced by the average of the two torsion angles $\mathrm{N}(1)-\mathrm{C}(1)-\operatorname{Ir}(1)-\mathrm{I}(1)$ and $\mathrm{N}(2)-\mathrm{C}(1)-\operatorname{Ir}(1)-\mathrm{I}(1), 88.12^{\circ}$. The Ir-C(carbene) bond distance is 2.007(4) A. Interestingly, the plane of the imidazolylidene deviates from the plane formed by the hexacyclic backbone by $14.75^{\circ}$.

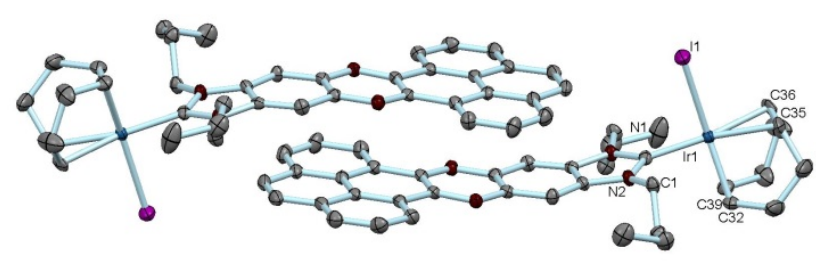

Figure 1. Molecular structure of complex 5- $\mathrm{H}$, showing the $\pi$ stacking between the hexacyclic backbone of two molecules. Hydrogen atoms have been omitted for clarity. Ellipsoids at $50 \%$ probability. Selected bond distances $(\AA)$ and angles $\left({ }^{\circ}\right)$. $\operatorname{Ir}(1)-\operatorname{I}(1) \quad 2.6721(4), \quad \operatorname{Ir}(1)-C(1) \quad 2.007(4), \quad \operatorname{Ir}(1)-C(32) \quad 2.113(5)$, $\operatorname{Ir}(1)-C(35) 2.203(4), \operatorname{Ir}(1)-C(36) 2.197(4), \operatorname{Ir}(1)-C(39) 2.120(5)$, $\mathrm{C}(1)-\operatorname{Ir}(1)-\mathrm{I}(1)$ 88.35(13), N(1)-C(1)-N(2) 106.1(4).

The molecular structure of complex 7 (Figure 2), confirms the coordination of the acetonaphtho[1,2b]quinoxaline[11,12-d]imidazol-2-ylidene ligand to the
iridium(I) fragment. A iodide and a COD ligand complete the coordination sphere about the metal. The polyaromatic ligand contains all six cycles in the same plane. The Ir-C(carbene) bond distance is 2.016(4) A. The NHC ligand is quasi-orthogonally oriented with respect to the coordination plane of the metal, as indicated by the average of the two torsion angles $\mathrm{N}(1)-\mathrm{C}(1)-\operatorname{Ir}(1)-\mathrm{I}(1)$ and $\mathrm{N}(2)$ $\mathrm{C}(1)-\operatorname{Ir}(1)-\mathrm{I}(1), 89 \cdot 37^{\circ}$. As seen for the molecular structure of $5-\mathrm{H}$, the crystal packing of $\mathbf{7}$ shows that there is a onedimensional $\pi$-stacking interaction between pairs of molecules, which are disposed in an antiparallel fashion, at a distance of $3.47 \AA$, which is slightly longer to that shown by $5-\mathrm{H}$.

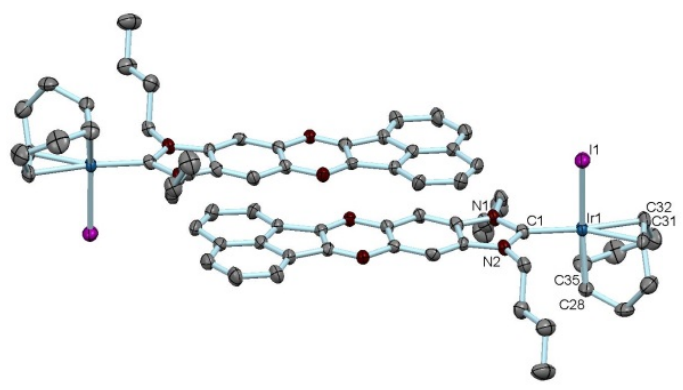

Figure 2. Molecular structure of complex 7 , showing the $\pi$ stacking between the hexacyclic backbone of two molecules. Hydrogen atoms and solvent $(\mathrm{MeOH})$ have been omitted for clarity. Ellipsoids at 50 \% probability. Selected bond distances $(\AA)$ and angles $\left({ }^{\circ}\right) . \operatorname{Ir}(1)-I(1) 2.6704(4), \operatorname{Ir}(1)-C(1) 2.016(4)$, $\operatorname{Ir}(1)-C(32) 2.216(4), \operatorname{Ir}(1)-C(35) 2.107(4), \operatorname{Ir}(1)-C(28) 2.134(4)$, $\operatorname{Ir}(1)-C(31) \quad 2.178(4), \quad C(1)-\operatorname{Ir}(1)-I(1) \quad 89.18(11), \quad \mathrm{N}(1)-C(1)-N(2)$ $106.2(3)$.

The reaction of $\mathbf{4}$ and $\mathbf{6}$ with carbon monoxide in methylene chloride, afforded the related carbonyl complexes $\mathbf{8}$ and 9, respectively (Scheme 2). The ${ }^{1} \mathrm{H}$ NMR spectra of these complexes indicate the absence of the signals due to the COD ligand, as a first indication that the substitution has been produced. The presence of the carbonyl ligands is confirmed by the representative signals in the ${ }^{13} \mathrm{C}$ NMR spectra. The signals due to the metallated carbene carbon are observed at 191.7, 181.2 and $189.7 \mathrm{ppm}$, respectively. The infrared spectra of $\mathbf{8}$ and $\mathbf{9}$ in $\mathrm{CH}_{2} \mathrm{Cl}_{2}$ exhibit the $\mathrm{C}-\mathrm{O}$ stretching bands at 2071.2 and $1989.2 \mathrm{~cm}^{-1}$ for $8-\mathrm{H}, 2072.1$ and $1989.2 \mathrm{~cm}^{-1}$ for 8 -tBu, and 2071.2 and $1989.2 \mathrm{~cm}^{-1}$ for 9 . These frequencies allowed us to estimate the corresponding Tolman Electronic Parameters ${ }^{15}$ (TEPs) as 2055.6, 2056.0 and $2055.6 \mathrm{~cm}^{-1}$, for $8-\mathrm{H}, 8-\mathrm{tBu}$ and 9, respectively, by using the well-known correlations. ${ }^{16}$

Once the new complexes were fully characterized, we decided to approach a study aiming to determine whether the addition of $\pi$-stacking additives may have some influence on the electron-donating character of our polyaromatic-NHC-based ligands. In a recent work, we demonstrated how the presence of $\pi$-stacking additives influenced the catalytic activity of a palladium complex bearing an $\mathrm{N}$-heterocyclic carbene with a fused pyrene. ${ }^{6 \mathrm{a}}$ Although we demonstrated that the additives effectively formed $\pi$-stacking adducts with the ligand, and proved that this interaction yielded important implications in the 
electron-donating character of the ligand, we did not make a detailed study in order to quantify the magnitude of this effect. With the preparation of the carbonyl complexes 8 and 9, bearing extended polyaromatic ligands, together with our previously described iridium-dicarbonyl NHC-based complex with a pyrene-fused fragment, ${ }^{6 \mathrm{~b}}$ we thought that we have an excellent opportunity to assess the modification of the electronic properties of the ligand by studying the variation of the TEP values upon addition of $\pi$-stacking additives. In order to approach this study, we first derived the TEP values of a model $\mathrm{LNi}(\mathrm{CO})_{3}$ complex by DFT calculations, in which $\mathrm{L}$ is our previously described pyrene-based NHC ligand (Figure 3). The relative energies for the optimized structures with the $\pi$ stacking additives indicate that the energies of the $\pi$ stacking interaction are $\mathbf{- 1 5 . 2}$ and $-9.6 \mathrm{kcal} / \mathrm{mol}$, for the adducts formed by addition of pyrene and hexafluorobenzene, respectively. These energies may be attributed to the $\pi$-stacking energies in the gas phase. A more interesting information may be derived from the comparison of the calculated TEP values. The TEP value for the pyreneimidazolylidene ligand without any interaction with the $\pi$-stacking arenes, is $2056.1 \mathrm{~cm}^{-1}$. The formation of the $\pi$ stacking complexes results in a significant variation of the TEP value, by -3.8 or $2.3 \mathrm{~cm}^{-1}$, depending on whether pyrene or hexafluorobenzene are added, respectively (the TEP values for the system with added pyrene is $2052.3 \mathrm{~cm}^{-}$ '; for the system with hexafluorobenzene $2058.4 \mathrm{~cm}^{-1}$ ). This actually implies that the electron-donating character of the ligand may be theoretically modified by a total of $6.1 \mathrm{~cm}^{-1}$, by simply choosing the right additive.

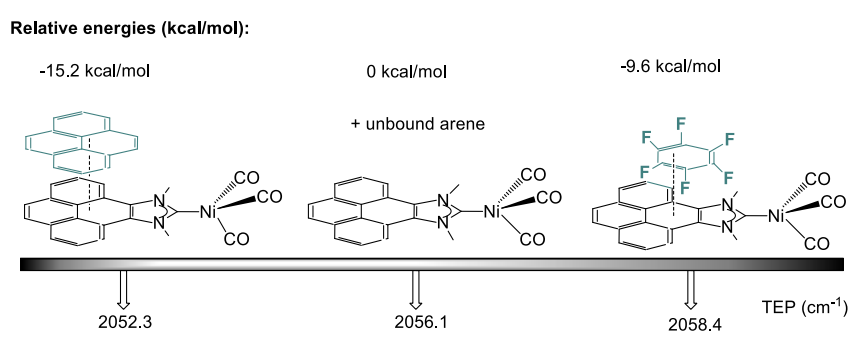

Figure 3. Variation of the TEP values of a pyrene-fused NHC ligand upon addition of pyrene or hexafluorobenzene. The energies correspond to the optimized structures with pyrene or hexafluorobenzene forming the $\pi$-stacking adducts, relative to the situation in which these molecules do not interact with the metal complex. Calculations were carried out in Gaussiano9 (revision D.1) using the Mo6L functional, tight optimizations, and the ultrafine integration grid (a pruned $(99,590)$ grid $)$.

We wanted to know if this observation may be experimentally verified by studying the variation of the $\mathrm{C}-\mathrm{O}$ stretching frequencies of the complexes bearing polyaromatic ligands, upon the addition of pyrene or hexafluorobenzene. For our study we decided to perform the IR spectra of the $\left[\operatorname{IrClL}(\mathrm{CO})_{2}\right]$ complexes shown in Table 2, where $\mathrm{L}$ is the NHC ligand with the fused polyaromatic systems. For comparative purposes we also performed the
IR spectra under the same conditions, of complexes bearing the related imidazolylidene and benzimidazolylidene ligands. As can be seen from the results shown in Table 2, the addition of pyrene or hexafluorobenzene has a significant effect on the variation of the $\mathrm{CO}$ stretching frequencies of the complexes under study. This variation can be considered negligible, for the case of the imidazolylidenebased complex, for which a small variation of -0.4 or 0.5 (for the addition of pyrene or hexafluorobenzene, respectively) is observed. This result is in agreement with the lower $\pi$-stacking ability of the NHC ligand of this complex, in which the polyaromatic system is not present. The variation is slightly increased for the experiments carried out with the benzimidazolylidene ligand, and becomes more pronounced for the complexes bearing the pyrene moieties. Although the variations may seem small (maximum variations of $1.5 \mathrm{~cm}^{-1}$ are observed, compared to the situation without additive), it has to be taken into account that the results perfectly match with the predicted DFT calculated results, for which the addition of pyrene consistently produces a decrease of the $\mathrm{CO}$ stretching frequencies, while the addition of hexafluorobenzene has the opposite effect, by increasing the frequency. It is also important to point out, that for the cases where a pyrene fragment is present in the ligand, a maximum and non-negligible variation of the frequency of $2.9 \mathrm{~cm}^{-1}$ can be detected, relative to the comparison of the situations in which pyrene or hexafluorobenzene are added. This variation is about six times the $0.5 \mathrm{~cm}^{-1}$ precision of the routine IR experiment, which is limited by the bandwidth of the respective absorptions and the spectrometer resolution. As a reference for comparing the magnitude of the electronic modification of the ligand, it may be taken into account that the electronic differences between N,N'dimethyl-imidazolylidene (IMe) and N,N'-dimethylbenzoimidazolylidene (two NHC ligands that are considered significantly different from their electronic points of view) are exactly of $2.9 \mathrm{~cm}^{-1}$, according to the comparison of their related calculated TEP values. ${ }^{17}$ These results suggest that the ligand post-modifies its electronic character in solution, by addition of the suitable aromatic additive.

Table 2. IR $\mathrm{C}-\mathrm{O}$ stretching frequencies of $\left[\operatorname{IrClL}(\mathrm{CO})_{2}\right]$ complexes. Effects of the addition of pyrene and hexafluorobenzene $^{\mathrm{a}}$

\begin{tabular}{|c|c|c|c|c|}
\hline$\left[\operatorname{IrClL}(\mathrm{CO})_{2}\right]$ & $\begin{array}{l}\text { Addi- } \\
\text { tive }\end{array}$ & $v(\mathrm{CO})^{\mathrm{b}}\left(\mathrm{cm}^{-1}\right)$ & $\begin{array}{c}v_{\mathrm{av}} \\
(\mathrm{CO}) \\
\left(\mathrm{cm}^{-1}\right)\end{array}$ & $\begin{array}{c}\Delta v_{\mathrm{av}} \\
(\mathrm{CO}) \\
\left(\mathrm{cm}^{-1}\right)\end{array}$ \\
\hline & - & $2065.4,1981.5$ & 2023.4 & o \\
\hline & Pyr & $2064.4,1981.5$ & 2023.0 & -0.4 \\
\hline & $\mathrm{C}_{6} \mathrm{~F}_{6}$ & $2065.4,1982.5$ & 2023.9 & 0.5 \\
\hline & - & $2068.3,1985.4$ & 2026.8 & o \\
\hline & Pyr & $2068.3,1984.4$ & 2026.3 & -0.5 \\
\hline
\end{tabular}




\begin{tabular}{|c|c|c|c|c|}
\hline & $\mathrm{C}_{6} \mathrm{~F}_{6}$ & $2069.3,1986.3$ & 2027.8 & 1.0 \\
\hline & - & $2067 \cdot 3,1985.4$ & 2026.3 & o \\
\hline & Pyr & $2066.4,1983.4$ & 2024.9 & -1.4 \\
\hline & $\mathrm{C}_{6} \mathrm{~F}_{6}$ & $2069.3,1986.3$ & 2027.8 & 1.5 \\
\hline & - & $2071.2,1989.2$ & 2030.2 & o \\
\hline & Pyr & $2070.2,1987.3$ & 2028.8 & -1.4 \\
\hline & $\mathrm{C}_{6} \mathrm{~F}_{6}$ & 2073.1, 1990.2 & 2031.6 & 1.4 \\
\hline & - & $2072.1,1989.2$ & 2030.7 & o \\
\hline & Pyr & $2071.2,1987 \cdot 3$ & 2029.2 & -1.5 \\
\hline $8-\mathrm{tBu}$ & $\mathrm{C}_{6} \mathrm{~F}_{6}$ & 2073.1, 1990.2 & 2031.6 & 0.9 \\
\hline & - & $2071.2,1989.2$ & 2030.2 & o \\
\hline & Pyr & $2070.2,1987.3$ & 2028.8 & -1.4 \\
\hline 9 & $\mathrm{C}_{6} \mathrm{~F}_{6}$ & $2072.1,1989.2$ & 2030.7 & 0.5 \\
\hline
\end{tabular}

${ }^{\mathrm{a}}$ IR data obtained in $\mathrm{CH}_{2} \mathrm{Cl}_{2}$ solutions of the complex with saturated solutions of the additive. ${ }^{\mathrm{b}}$ The resolution of the IR experiments is $0.5 \mathrm{~cm}^{-1}$.

In order to shed some more light into the nature of the binding between the polyaromatic-functionalized NHC complexes and pyrene (or hexafluorobenzene), we decided to study their interaction by means of ${ }^{1} \mathrm{H}$ NMR spectroscopy. The addition of increasing amounts of hexafluorobenzene to a solution of $8-\mathrm{H}$, results in the shifting of a signal due to two aromatic protons of the pyrene core, which moves to lower frequencies, indicating that the $\pi-\pi$ interaction between hexafluorobenzene and $8-\mathrm{H}$ is mainly produced through this part of the molecule. When the same set of experiments is carried out by adding pyrene (instead of hexafluorobenzene), the signal due to the protons of the phenyl ring of the phenanthro[4,5abc]phenazino[11,12-d]imidazol-2-ylidene ligand shifts, although this time the movement is toward lower frequencies. This observation is in agreement with the deshielding or shielding of the proton, depending on the addition of hexafluorobenzene or pyrene, respectively. The shift of one of the signals on the ${ }^{1} \mathrm{H}$ NMR is an indication that the formation of the $\pi$-stacking adducts is fast on the NMR timescale, and therefore only a time averaged signal of the free and associated molecules is observed. This situation is identical to the one that can be found in host-guest chemistry, for which the stoichiometry of the host-guest complex can be determined by using the method of continuous variations (MCV), also known as the method of Job. ${ }^{18}$ For the determination of the stoichiometry of the $\pi$-stacking aggregates, we first prepared a series of solutions of 8 - $\mathrm{H}$ and pyrene $\left(\right.$ or $\mathrm{C}_{6} \mathrm{~F}_{6}$ ) in varying proportions, so that a complete range of mole ratios were sampled, while maintaining the total concentration, $[\mathbf{8}-\mathrm{H}]$ $+[\pi$-stacking additive $]$, constant for each solution (see Supplementary Information for further details). ${ }^{18 c, 18 d}$ This allowed us to determine that the maximum shift on $\delta$ was achieved when the molar fraction is 0.5 , and therefore the stoichiometry of the aggregates is 1:1. Once the stoichiometry was determined, the associate constants were estimated by using the Benesi-Hildebrand treatment, ${ }^{19}$ which when applied to NMR spectroscopy stablishes that the shift of the NMR signal is related with the associate constant by virtue of the equation:

$1 / \Delta \delta=1 /\left(K_{a} \Delta \delta_{\max }[H]\right)+1 / \Delta \delta_{\max }$

where, in our case, $[\mathrm{H}]$ is the concentration of the $\pi$ stacking additive, pyrene or hexafluorobenzene. The resulting plots are shown in Figure 4, where it can be estimated that the association constants for the formation of the $\pi$-stacking aggregates of 8 - $\mathrm{H}$ with pyrene and hexafluorobenzene, are $2.21 \mathrm{M}^{-1}$ and $0.13 \mathrm{M}^{-1}$, respectively. These values are in agreement with our theoretical calculations, which established a higher $\pi$-stacking affinity of pyrene compared to the one shown by hexafluorobenzene, with the $\mathrm{Ni}(\mathrm{CO})_{3}$ complex bound to a pyrene-fused NHC (Figure 3).
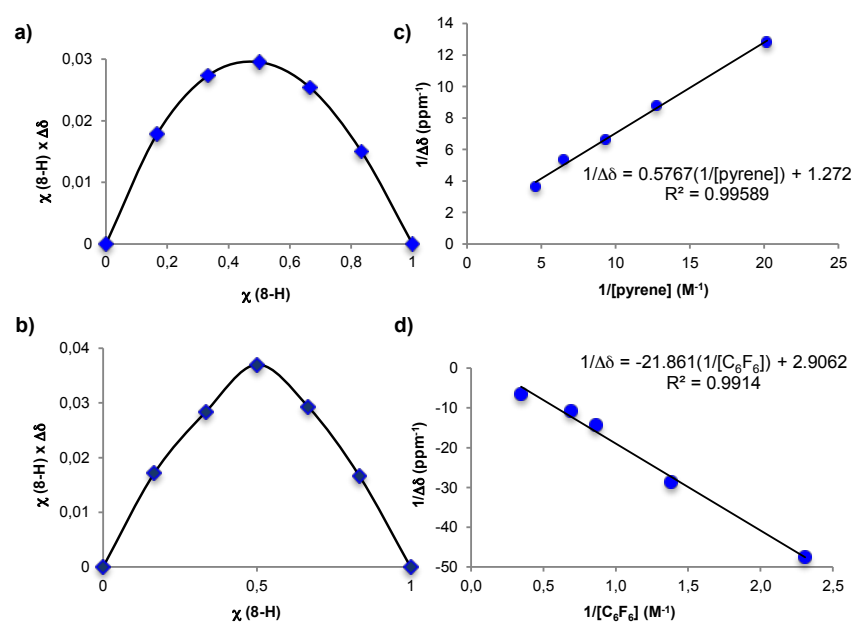

d)

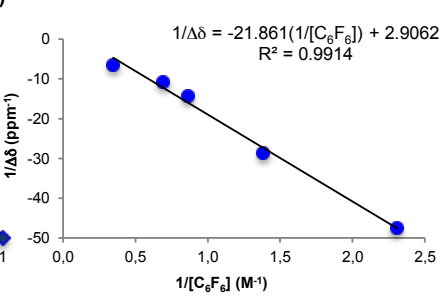

Figure 4. Job plot for the determination of the stoichiometry of the aggregates complex 8-H/pyrene (a) and $\mathrm{C}_{6} \mathrm{~F}_{6}$ (b). Determination of the association constants of $8-\mathrm{H}$ with pyrene (c) and $\mathrm{C}_{6} \mathrm{~F}_{6}(\mathrm{~d})$. c) Plot of $1 / \Delta \delta$ vs $1 /$ [pyrene]. The BenesiHildebrand treatment gives $\Delta \delta_{\max }=0.79 \mathrm{ppm}$ and $K_{\mathrm{a}}=\mathbf{2 . 2 1}$ $\mathrm{M}^{-1}$. d) Plot of $1 / \Delta \delta \delta_{1} /\left[\mathrm{C}_{6} \mathrm{~F}_{6}\right]$. The Benesi-Hildebrand treatment gives $\Delta \delta_{\max }=0.344 \mathrm{ppm}$ and $K_{\mathrm{a}}=0.13 \mathrm{M}^{-1}$.

\section{Conclusions}

In this work we have described the preparation of a series of iridium complexes containing phenanthro[4,5abc]phenazino[11,12-d]imidazol-2-ylidene and acetonaphtho[1,2-b]quinoxaline[11,12-d]imidazol-2-ylidene ligands. The new complexes are decorated with highly extended polyaromatic systems. We observed that the CO IRstretching frequencies of the new complexes obtained, are influenced by the nature of $\pi$-stacking additives, and therefore the electronic nature of the NHCs with the polyaromatic backbones can be fine-tuned by the addi- 
tion of the suitable additive. Addition of pyrene, results in the slight decrease of the $\mathrm{CO}$ stretching frequency, while the addition of hexafluorobenzene causes exactly the opposite effect. This observation is in agreement with the computational calculations on the formation of $\pi$ stacking aggregates between a complex formed by $\mathrm{Ni}(\mathrm{CO})_{3}$ bound to a $\mathrm{N}$-heterocyclic carbene with a fused pyrene, for which the calculated TEP values are increased upon addition of pyrene, and decreased upon addition of hexafluorobenzene.

The $\pi$-stacking affinities of one of the new complexes, with pyrene and hexafluorobenzene were unambiguously quantified by means of ${ }^{1} \mathrm{H}$ NMR spectroscopy. The determination of the association constants by using the BenesiHildebrand data treatment, allowed us to establish that pyrene forms more stable aggregates than hexafluorobenzene, as seen by the higher $K_{\mathrm{a}}$ shown by the first one.

Our results indicate that the electronic properties of certain type of ligands (those having extendedpolyconjugated systems), may be tuned if the proper $\pi$ stacking additives are chosen. We already demonstrated that this effect has important consequences in the modification of the catalytic activity of metal complexes containing NHC ligands fused to polyaromatic fragments. With this work, we clarified and quantified the nature of this type of effect, which be taken into account in the design of future homogeneous catalysts.

\section{ASSOCIATED CONTENT}

Supporting Information. Experimental procedures and characterization data. CIF files of the molecular structures of complexes $5-\mathrm{H}$ and 7 , NMR spectra of the new complexes, relevant sections of the ${ }^{1} \mathrm{H}$ NMR spectra for the application of the method of continuous variations (MCV), computational details. This material is available free of charge via the Internet at http://pubs.acs.org."

\section{AUTHOR INFORMATION}

\section{Corresponding Author}

Eduardo Peris (eperis@uji.es) and Macarena Poyatos (poyatosd@uji.es)

\section{Author Contributions}

The manuscript was written through contributions of all authors. / All authors have given approval to the final version of the manuscript. / \$These authors contributed equally. (match statement to author names with a symbol)

\section{ACKNOWLEDGMENT}

We gratefully acknowledge financial support from MEC of Spain (CTQ2011-24055/BQU). The authors are grateful to the Serveis Centrals d'Instrumentació Científica (SCIC) of the Universitat Jaume I for providing with spectroscopic and XRay facilities. We would also like to thank the Ramón y Cajal (M.P) and the Santiago Grisolía (H.V.) programs. We are very thankful to Prof. Dmitri Gusev (Wilfrid Laurier University) for the computational calculations.

\section{REFERENCES}

(1) a) Schuster, O.; Mercs, L.; Albrecht, M. Chimia 2010, 64, 184187; b) Mercs, L.; Albrecht, M. Chem. Soc. Rev. 2010, 39, 19031912.

(2) a) Visbal, R.; Concepcion Gimeno, M. Chem. Soc. Rev. 2014, 43, 3551-3574; b) Lin, J. C. Y.; Huang, R. T. W.; Lee, C. S.; Bhattacharyya, A.; Hwang, W. S.; Lin, I. J. B. Chem. Rev. 2oog, 109, 3561-3598.

(3) a) Mormul, J.; Steimann, M.; Maichle-Mossmer, C.; Nagel, U. Eur. J. Inorg. Chem. 2013, 3421-3428; b) Ullah, F.; Kindermann, M. K.; Jones, P. G.; Heinicke, J. Organometallics 2009, 28, 2441-2449; c) Tapu, D.; Owens, C.; VanDerveer, D.; Gwaltney, K. Organometallics 2009, 28, 270-276.

(4) a) Ciancaleoni, G.; Biasiolo, L.; Bistoni, G.; Macchioni, A.; Tarantelli, F.; Zuccaccia, D.; Belpassi, L. Organometallics 2013, 32, 4444-4447; b) Butorac, R. R.; Al-Deyab, S. S.; Cowley, A. H. Molecules 2011, 16, 2285-2292; c) Butorac, R. R.; Al-Deyab, S. S.; Cowley, A. H. Molecules 2011, 16, 3168-3178; d) Vasudevan, K. V.; Butorac, R. R.; Abernethy, C. D.; Cowley, A. H. Dalton Trans. 2010, 39, 7401-7408; e) Tu, T.; Sun, Z. M.; Fang, W. W.; Xu, M. Z.; Zhou, Y. F. Org. Lett. 2012, 14, 4250-4253; f) Tu, T.; Fang, W. W.; Jiang, J. Chem. Commun. 2011, 47, 12358-1236o.

(5) a) Prades, A.; Peris, E.; Alcarazo, M. Organometallics 2012, 31, 4623-4626; b) Guisado-Barrios, G.; Hiller, J.; Peris, E. Chem. Eur. J. 2013, 19, 10405-10411.

(6) a) Valdés, H.; Ujaque, G.; Poyatos, M.; Peris, E. Chem. Eur. J. 2015, 21, 1578-1588; b) Valdés, H.; Poyatos, M.; Peris, E. Organometallics 2014, 33, 394-401.

(7) a) Gonell, S.; Poyatos, M.; Peris, E. Angew. Chem. Int. Ed. 2013, 52, 7009-7013; b) Gonell, S.; Alabau, R. G.; Poyatos, M.; Peris, E. Chem. Commun. 2013, 49, 7126-7128.

(8) a) Keller, M.; Colliere, V.; Reiser, O.; Caminade, A. M.; Majoral, J. P.; Ouali, A. Angew. Chem. Int. Ed. 2013, 52, 36263629; b) Wittmann, S.; Schatz, A.; Grass, R. N.; Stark, W. J.; Reiser, O. Angew. Chem. Int. Ed. 2010, 49, 1867-1870; c) Sabater, S.; Mata, J. A.; Peris, E. ACS Catal. 2014, 4, 2038-2047; d) Lee, J. S.; Lee, S. H.; Kim, J.; Park, C. B. J. Mater. Chem. A 2013, 1, 10401044; e) Ruiz-Botella, S.; Peris, E. Organometallics 2014, 33, 55095516.

(9) Kumar, A.; Ghosh, P. Eur. J. Inorg. Chem. 2012, 3955-3969.

(10) Cesar, V.; Lugan, N.; Lavigne, G. Chem. Eur. J. 2010, 16, 1143211442.

(11) a) Ward, R. A.; Kettle, J. G. J. Med. Chem. 2o11, 54, 4670-4677; b) Pitt, W. R.; Parry, D. M.; Perry, B. G.; Groom, C. R. J. Med. Chem. 2009, 52, 2952-2963; c) Lovering, F.; Bikker, J.; Humblet, C. J. Med. Chem. 2009, 52, 6752-6756.

(12) Tapu, D.; McCarty, Z.; Hutchinson, L.; Ghattas, C.; Chowdhury, M.; Salerno, J.; VanDerveer, D. J. Organomet. Chem. 2014, 749, 134-141.

(13) Kirkbrig.Gf; Lima, C. G. D. Analyst 1974, 99, 338-354.

(14) Gonell, S.; Poyatos, M.; Peris, E. Chem. Eur. J. 2014, 20, 97169724 .

(15) Tolman, C. A. Chem. Rev. 1977, 77, 313-348.

(16) a) Nelson, D. L.; Nolan, I. P. Chem. Soc. Rev. 2013, 6723-6753; b) Chianese, A. R.; Li, X. W.; Janzen, M. C.; Faller, J. W.; Crabtree, R. H. Organometallics 2003, 22, 1663-1667; c) Kelly, R. A., III; Clavier, H.; Giudice, S.; Scott, N. M.; Stevens, E. D.; Bordner, J.; Samardjiev, I.; Hoff, C. D.; Cavallo, L.; Nolan, S. P. Organometallics 2008, 27, 202-210.

(17) Gusev, D. G. Organometallics 2009, 28, 6458-6461.

(18) a) Renny, J. S.; Tomasevich, L. L.; Tallmadge, E. H.; Collum, D. B. Angew. Chem. Int. Ed. 2013, 52, 11998-12013; b) Fielding, L. Tetrahedron 200o, 56, 6151-6170; c) Gil, V. M. S.; Oliveira, N. C. J. Chem. Educ. 1990, 67, 473-478; d) Job, P. Annales De Chimie France 1928, 9, 113-203.

(19) Benesi, H. A.; Hildebrand, J. H. J. Am. Chem. Soc. 1949, 71, 2703-2707. 
SYNOPSIS TOC (Word Style "SN_Synopsis_TOC"). If you are submitting your paper to a journal that requires a synopsis graphic and/or synopsis paragraph, see the Instructions for Authors on the journal's homepage for a description of what needs to be provided and for the size requirements of the artwork.

To format double-column figures, schemes, charts, and tables, use the following instructions:

Place the insertion point where you want to change the number of columns

From the Insert menu, choose Break

Under Sections, choose Continuous

Make sure the insertion point is in the new section. From the Format menu, choose Columns

In the Number of Columns box, type 1

Choose the OK button

Now your page is set up so that figures, schemes, charts, and tables can span two columns. These must appear at the top of the page. Be sure to add another section break after the table and change it back to two columns with a spacing of 0.33 in.

Table 1. Example of a Double-Column Table

\begin{tabular}{|l|l|l|l|l|l|l|l|}
\hline Column 1 & Column 2 & Column 3 & Column 4 & Column 5 & Column 6 & Column 7 & Column 8 \\
\hline & & & & & & & \\
\hline
\end{tabular}

Authors are required to submit a graphic entry for the Table of Contents (TOC) that, in conjunction with the manuscript title, should give the reader a representative idea of one of the following: A key structure, reaction, equation, concept, or theorem, etc., that is discussed in the manuscript. Consult the journal's Instructions for Authors for TOC graphic specifications.

\section{Insert Table of Contents artwork here}

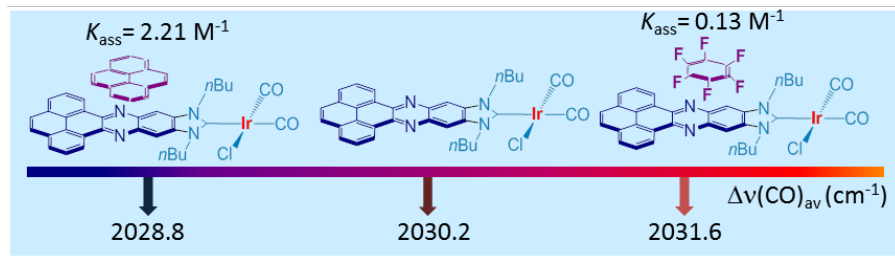

A series of Ir complexes with different NHC ligands bearing rigid polyaromatic systems have been obtained. The electrondonating character of these ligands is sensitive to the presence of $\pi$-stacking additives, such as pyrene and hexafluoroben- 